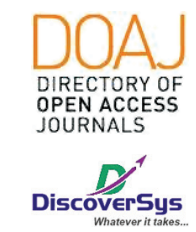

Published by DiscoverSys

\title{
Gambaran tingkat pengetahuan tentang Periksa Payudara Sendiri (SADARI) pada mahasiswa Fakultas Kedokteran Universitas Udayana, Bali, Indonesia angkatan 2013-2015
}

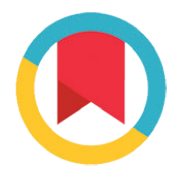

CrossMark

\author{
Annisa Alviariza, ${ }^{1 *}$ Putu Anda Tusta Adiputra ${ }^{2}$
}

\section{ABSTRACT}

Background: BSE (Breast Self-Examination) is a systematic approach to inspection and palpation examination of the chest and armpit independently. BSE can be used as a means of early detection of breast cancer using a simple, inexpensive and safe. This study aims to determine the level of knowledge about BSE among students of Medical Education Faculty of Medicine Udayana University class of 2013, 2014 and 2015. Methods: A descriptive cross-sectional study was conducted among 285 respondents at Faculty of Medicine, Medical Education Program class of 2013,2014, and 2015. The instrument used in this study was a valid and reliable questionnaire to identify the respondents' knowledge about breast cancer and BSE. Questionnaire data that has been collected is processed in the form of descriptive data analysis by calculating proportion and percentages. Data were analyzed using SPSS version 17 for Windows.
Results: The highest average score about SADARI were obtained in Class 2013 (75\%), followed by Class 2014 (72\%), and Class 2015 (67\%) students. A high level of knowledge criteria about SADARI also suggest similar results where Class 2013 was having the highest percentage (63\%), followed by Class 2014 (25\%), and Class 2015 (8\%). However, based on the overall results, the students had a moderate score of $66 \%$. Besides, according to the questions on the questionnaire, the students had an excellent average score about signs and symptoms (83\%), cause (79\%), and stage of breast cancer (79\%).

Conclusion: Class 2013 had a good level of knowledge regarding SADARI compared with Class 2014 and 2015. However, overall students still at a moderate average score of SADARI.

Keywords: BSE, Level of Knowledge, Breast Cancer, Early Detection.

Cite This Article: Alviariza, A., Adiputra, P.A.T. 2020. Gambaran tingkat pengetahuan tentang Periksa Payudara Sendiri (SADARI) pada mahasiswa Fakultas Kedokteran Universitas Udayana, Bali, Indonesia angkatan 2013-2015. Intisari Sains Medis 11(1): 190-193. D0I: 10.15562/ism.v11i1.531

\section{ABSTRAK}

Latar Belakang: SADARI (Periksa Payudara Sendiri) adalah metode sistematik untuk pemeriksaan inspeksi dan palpasi dada dan ketiak secara mandiri. SADARI dapat digunakan sebagai cara deteksi dini kanker payudara dengan menggunakan cara yang sederhana, murah dan aman. Penelitian ini bertujuan untuk mengetahui tingkat pengetahuan mengenai SADARI Mahasiswa Pendidikan Dokter Fakultas Kedokteran Universitas Udayana angkatan 2013, 2014 dan 2015.

Metode: Sebuah studi potong lintang deskriptif dilakukan terhadap 285 responden di Fakultas Kedokteran, Program Pendidikan Kedokteran kelas 2013, 2014, dan 2015. Instrumen yang digunakan dalam penelitian ini adalah kuesioner yang sahih dan reliabel untuk mengidentifikasi pengetahuan responden tentang kanker payudara dan BSE. Data kuesioner yang telah dikumpulkan diolah dalam bentuk analisis data deskriptif dengan menghitung proporsi dan persentase. Data dianalisis menggunakan SPSS versi 17 untuk Windows.

Hasil: Nilai rata-rata tertinggi tentang SADARI diperoleh pada siswa di Kelas 2013 (75\%), diikuti oleh Kelas 2014 (72\%), dan Kelas 2015 (67\%). Kriteria tingkat pengetahuan tinggi tentang SADARI juga memberikan hasil yang serupa di mana Kelas 2013 memiliki persentase tertinggi (63\%), diikuti oleh Kelas 2014 (25\%), dan Kelas 2015 (8\%). Namun, berdasarkan hasil keseluruhan, para siswa memiliki skor sedang $66 \%$. Selain itu, menurut pertanyaan pada kuesioner, para siswa memiliki skor rata-rata yang sangat baik tentang tanda dan gejala (83\%), penyebab (79\%), dan stadium kanker payudara (79\%).

Kesimpulan: Kelas 2013 memiliki tingkat pengetahuan yang baik tentang SADARI dibandingkan dengan Kelas 2014 dan 2015. Namun, keseluruhan siswa masih berada pada skor rata-rata SADARI yang moderat. Udayana, Bali, Indonesia; annisaalviariza@gmail.com 


\section{PENDAHULUAN}

Kanker payudara adalah tumor ganas yang memulai pertumbuhannya pada payudara. Tumor ganas adalah sekumpulan sel ganas yang dapat tumbuh pada jaringan normal dan bermetastasis pada berbagai area di tubuh. ${ }^{1}$ Kanker payudara merupakan salah satu jenis kanker terbanyak di Indonesia. Berdasarkan data dari Kementrian Kesehatan RI, penyakit kanker serviks dan payudara merupakan penyakit kanker dengan prevalensi tertinggi di Indonesia pada tahun 2013, yaitu kanker serviks sebesar $0,8 \%$ dan kanker payudara sebesar $0,5 \%{ }^{2}$ Tingginya kasus kematian akibat kanker payudara di Indonesia seharusnya dapat dicegah dengan deteksi dini. Berdasarkan dari American Cancer Society, terdapat penurunan kasus kematian akibat kanker payudara semenjak tahun 1989, pada wanita dibawah 50 tahun. ${ }^{3}$ Penurunan kasus kematian ini didapatkan dari hasil deteksi dini melalui screening, peningkatan kesadaran dan juga pengobatan. ${ }^{3}$ Selain tingginya kasus, masalah penyakit kanker di Indonesia yang lainnya adalah hampir $70 \%$ penderita penyakit ini ditemukan dalam keadaan stadium yang sudah lanjut. ${ }^{4}$ Kenyataan yang ada antara lain sebagian besar kanker payudara yang berobat ke RS/dokter sudah dalam keadaan stadium lanjut $(>50 \%) .{ }^{5} \mathrm{Hal}$ ini menunjukan kurangnya kesadaran masyarakat dalam hal deteksi dini kanker.

Merujuk kepada masalah diatas, solusi yang dapat ditawarkan adalah deteksi dini kanker payudara dengan menggunakan cara yang sederhana, murah dan aman yaitu Periksa Payudara Sendiri (SADARI). SADARI adalah metode sistematik untuk pemeriksaan inspeksi dan palpasi dada dan ketiak secara mandiri. ${ }^{6}$ American Cancer Society menganjurkan wanita yang berusia lebih dari 20 tahun untuk melakukan SADARI tiap 3 bulan. $^{7}$ Saat ini ada kecenderungan kanker payudara dialami oleh perempuan dengan usia (15-20an), ini berarti tidak ada kata terlalu dini untuk memulai memberikan pendidikan SADARI secara rutin (7-10 hari setelah haid) setiap bulan.

Pada wanita yang melakukan SADARI dapat menemukan kanker payudara pada stadium yang lebih awal dan lebih memungkikan untuk diterapi lebih awal sehingga menurunkan resiko untuk meninggal akibat kanker payudara. ${ }^{8}$ Studi mengenai deteksi dini kanker payudara sendiri juga sedang diteliti oleh International Agency for Research on Cancer lebih lanjut dan menunjukan bahwa wanita yang melakukannya dapat menemukan tumor payudaranya saat ukuran tumor masih kecil sehingga wanita ini memiliki prognosis untuk sembuh. ${ }^{8}$

Merujuk pada permasalahan tingginya insiden kanker payudara dan secara teori terdapat hubungan Periksa Payudara Sendiri (SADARI) dengan prognosis yang lebih baik pada kanker payudara, maka diperlukan suatu penelitian untuk mengetahui tingkat pengetahuan seseorang terhadap tindakan SADARI sebagai deteksi dini sendiri kanker payudara. Seorang dokter pelayanan primer mempunyai peran untuk mengedukasi masyarakat. Teknik SADARI ini penting diketahui oleh para dokter layanan primer sebagai deteksi dini untuk mengetahui adanya tumor atau kanker payudara. Oleh karena itu, pada penelitian ini saya bertujuan untuk mengetahui tingkat pengetahuan mengenai teknik SADARI pada mahasiswa Pendidikan Dokter Fakultas Kedokteran Universitas Udayana yang merupakan calon dokter di masa mendatang.

\section{METODE}

Rancangan penelitian yang digunakan adalah deskriptif potong lintang. Pengukuran variabel-variabel pada desain studi ini hanya dilakukan satu kali pada satu titik waktu.

Populasi target pada penelitian ini adalah seluruh mahasiswa Program Studi Pendidikan Dokter Fakultas Kedokteran Universitas Udayana. Populasi terjangkau pada penelitian ini adalah seluruh mahasiswa Program Studi Pendidikan Dokter Fakultas Kedokteran Universitas Udayana angkatan 2013, 2014 dan 2015.

Kriteria inklusi pada penelitian ini adalah mahasiswa Program Studi Pendidikan Dokter Fakultas Kedokteran Universitas Udayana angkatan 2013, 2014 dan 2015 yang berusia 18-23 tahun dan bersedia untuk terlibat dalam penelitian. Sedangkan untuk kriteria ekslusinya adalah mahasiswa yang tidak memenuhi kriteria inklusi.

Teknik penghitungan jumlah sampel, dihitung menggunakan rumus minimal sampel yang dibutuhkan untuk penelitian jenis deskriptif cross-sectional, lalu didapatkan minimal sampel yang dibutuhkan adalah 285 mahasiswa. Adapun tahapan yang diambil dalam penelitian ini diawali dengan persiapan penelitian yaitu pembuatan proposal, memohon ijin kepada pihak yang berwenang pada masing-masing salon yang berada di wilayah Denpasar Selatan untuk melaksanakan penelitian, memohon kelayakan etik terhadap penelitian yang akan dilaksanakan, menyiapkan persetujuan tertulis atau informed consent, dan menyiapkan kuisioner untuk pengambilan data dari responden, sedangkan tahap pelaksanaan penelitian berupa mencocokkan data yang telah didapatkan sesuai dengan kriteria inklusi dan kriteria eksklusi penelitian, memberikan lembar kuisioner kepada responden.

Data yang telah terkumpul tersebut kemudian diolah dan dianalisis dengan menggunakan 
analasis univariat untuk mengetahui bagaimana distribusi frekuensi serta persentase setiap variabel yang diteliti. Adapun piranti lunak yang dipergunakan dalam analisis penelitian ini adalah SPSS versi 17 untuk Windows.

\section{HASIL}

Dari Tabel 1 menunjukan bahwa sebagian besar responden memiliki tingkat pengetahuan yang sedang. Responden yang mendapatkan hasil tingkat pengetahuan tentang SADARI yang tinggi sejumlah 90 responden (32\%), tingkat pengetahuan tentang SADARI sedang sejumlah 189 responden $(66 \%)$ dan tingkat pengetahuan tentang SADARI rendah sejumlah 6 responden (2\%) (Tabel 1).

Hasil penelitian ini menunjukkan bahwa terdapat perbedaan rata-rata nilai seputar pengetahuan SADARI terhadap masing-masing angkatan seperti yang terdapat pada Tabel 2. Nilai rata-rata terbaik tentang SADARI diperoleh pada Kelas 2013 sebesar 75\%, diikuti dengan Kelas 2014 (72\%), dan Kelas 2015 (67\%) (Tabel 2). Berdasarkan tingkat pengetahuan SADARI, Kelas 2013 juga memberikan proporsi tertinggi (63\%), diikuti dengan Kelas 2014 (25\%), dan Kelas 2015 (8\%) (Tabel 2).

Komponen pengetahuan terkait SADARI yang dinilai pada kuisioner mencakup beberapa aspek dimana memberikan hasil yang berbeda pada Tabel 2 . Akan tetapi secara garis besar, para siswa memiliki nilai tertinggi pada penilaian komponen pengetahuan seputar gejala dan tanda kanker payudara (83\%), diikuti dengan penyebab (79\%) maupun tingkatan atau stadium kanker payudara (79\%) (Tabel 2).

\section{PEMBAHASAN}

Hasil penelitian menunjukan bahwa sebagian besar responden memiliki tingkat pengetahuan tentang SADARI yang cukup baik atau sedang. Hal ini sesuai dengan latar belakang responden yang merupakan mahasiswa kedokteran umum yang sudah sepatutnya memiliki pengetahuan yang baik mengenai kanker payudara dan SADARI seperti pada penelitian sebelumnya., ${ }^{9,10}$

Dalam penelitian ini juga masih banyak responden yang memiliki tingkat pengetahuan SADARI yang kurang. Hal ini dapat terjadi karena berbagai faktor salah satunya adalah faktor pengalaman yang mempengaruhi pengetahuan seseorang dan tergantung pada ingatan seseorang pada saat pengisian kuesioner. ${ }^{11}$ Faktor lain yang juga berpengaruh adalah faktor usia. Semakin bertambah usia maka pengalaman dan pengetahuan akan semakin bertambah. Faktor lain yang dapat juga berpengaruh adalah tingkat pendidikan. ${ }^{12}$

Tabel 1 Tingkat pengetahuan siswa tentang SADARI secara keseluruhan

\begin{tabular}{lcc}
\hline Tingkat pengetahuan & Frekuensi (N=285) & Presentase (\%) \\
\hline Tinggi & 90 & 32 \\
Sedang & 189 & 66 \\
Rendah & 6 & 2 \\
\hline
\end{tabular}

Tabel 2 Tingkat pengetahuan berdasarkan angkatan dan distribusi frekuensi komponen pengetahuan SADARI

\begin{tabular}{lcccc}
\hline \multirow{2}{*}{ Variabel } & \multicolumn{2}{c}{ Tingkat Pengetahuan (N-285) } & \multirow{2}{*}{ Nilai Rata-Rata } \\
\cline { 2 - 3 } Angkatan & Tinggi (N,\%) & Sedang (N,\%) & Rendah (N,\%) & \\
$\quad$ Kelas 2013 & $59(63)$ & $36(37)$ & $0(0)$ & 75 \\
Kelas 2014 & $24(25)$ & $70(74)$ & $1(1)$ & 72 \\
Kelas 2015 & $7(8)$ & $83(87)$ & $5(5)$ & 67 \\
Komponen Pengetahuan & $121(42)$ & $0(0)$ & $164(58)$ & 63 \\
Pengertian & $108(38)$ & $0(0)$ & $177(62)$ & 63 \\
Epidemilogi & $204(72)$ & $59(20)$ & $22(8)$ & 79 \\
Penyebab & $144(51)$ & $124(43)$ & $17(6)$ & 78 \\
Faktor risiko & $166(58)$ & $91(32)$ & $28(10)$ & 83 \\
Tanda gejala & $8(3)$ & $52(18)$ & $225(79)$ & 79 \\
Tingkatan & $40(14)$ & $226(79)$ & $19(7)$ & 71 \\
Pencegahan dengan SADARI & & & & \\
\hline
\end{tabular}


Seseorang yang berpendidikan tinggi akan lebih mudah menerima informasi sehingga memiliki pengetahuan lebih luas daripada seseorang yang berpendidikan lebih rendah. ${ }^{13} \mathrm{Hal}$ ini sesuai dengan hasil penelitian yang menunjukan bahwa responden yang paling banyak mendapatkan tingkat pengetahuan tentang SADARI yang rendah adalah angkatan 2015. Responden tersebut memiliki akses informasi tentang prosedur SADARI yang lebih sedikit dan terbatas dibandingkan dengan angkatan diatasnya, sehingga wajar apabila pengetahuan responden angkatan 2015 mengenai SADARI lebih rendah dibandingkan angkatan diatasnya. Hasil penelitian inipun juga sesuai dengan studi yang dilakukan sebelumnya dimana usia memegang peranan penting terhadap pengetahuan seputar kesehatan. ${ }^{13-15}$

\section{SIMPULAN}

Dari hasil penelitian mengenai tingkat pengetahuan tentang SADARI yang dilakukan pada mahasiswa pendidikan dokter angkatan 2013, 2014 dan 2015 maka diperoleh kesimpulan sebagai berikut. Tingkat pengetahuan SADARI pada mahasiswa angkatan 2013, 2014 dan 2015 sudah baik. Hal ini ditunjukan dengan hasil presentase tingkat pengetahuan tinggi sebanyak $32 \%$, sedang sebanyak $66 \%$ dan rendah sebanyak $2 \%$. Tingkat pengetahuan masing-masing angkatan berbeda. Rata-rata nilai paling tinggi diperoleh oleh angkatan 2013 yaitu 75\%, yang kedua adalah angkatan 2014 dengan rata-rata nilai $72 \%$ dan terakhir angkatan 2015 yaitu $67 \%$.

\section{KONFLIK KEPENTINGAN}

Tidak ada

\section{ETIKA PENELITIAN}

Penelitian ini telah mendapatkan persetujuan etik dari Komisi Etik, Fakultas Kedokteran Universitas Udayana, Bali, Indonesia sebelum penelitian berjalan.

\section{PENDANAAN}

Penulis membiayai penelitian ini tanpa melibatkan pihak sponsor, beasiswa, ataupun sumber pendanaan lainnya.

\section{KONTRIBUSI PENULIS}

Semua penulis memiliki kontribusi yang sama dalam penulisan laporan penelitian ini baik dari penyusunan kerangka konsep hingga melaporkan hasil penelitian dalam bentuk publikasi.

\section{DAFTAR PUSTAKA}

1. Ataollahi MR, Sharifi J, Paknahad MR, Paknahad A. Breast cancer and associated factors: a review. J Med Life. 2015; 8(Spec Iss 4): 6-11.

2. Wahidin M, Noviani R, Hermawan S, Andriani V, Ardian A, Djarir H. Population-based cancer registration in Indonesia. Asian Pac J Cancer Prev. 2012;13(4):1709-1710.

3. Estrada SS. Review of the New American Cancer Society Guidelines for Breast Cancer Screening for Women at Average Risk. J Adv Pract Oncol. 2016;7(5):563-566.

4. Widodo I, Dwianingsih EK, Triningsih E, Utoro T, Soeripto. Clinicopathological features of indonesian breast cancers with different molecular subtypes. Asian Pac J Cancer Prev. 2014;15(15):6109-6113.

5. Oemiati R, Rahajeng E, Kristanto AY. Prevalensi Tumor dan Beberapa Faktor yang Memperngaruhinya di Indonesia. Buletin Penelitian Kesehatan. 2011;39(4):190-204

6. Baxter N; Canadian Task Force on Preventive Health Care. Preventive health care, 2001 update: should women be routinely taught breast self-examination to screen for breast cancer?. CMAJ. 2001;164(13):1837-1846.

7. Viale PH. The American Cancer Society Guidelines on Screening for Breast Cancer: What's New?. J Adv Pract Oncol. 2015;6(6):508-510.

8. Hackshaw AK, Paul EA. Breast self-examination and death from breast cancer: a meta-analysis. Br J Cancer. 2003;88(7):1047-1053.

9. Liu Y, Zhang J, Huang R, et al. Influence of occupation and education level on breast cancer stage at diagnosis, and treatment options in China: A nationwide, multicenter 10-year epidemiological study. Medicine (Baltimore). 2017;96(15):e6641.

10. Akhigbe AO, Omuemu VO. Knowledge, attitudes and practice of breast cancer screening among female health workers in a Nigerian urban city. BMC Cancer. 2009;9:203.

11. Taioli E, Joseph GR, Robertson L, Eckstein S, Ragin C. Knowledge and prevention practices before breast cancer diagnosis in a cross-sectional study among survivors: impact on patients' involvement in the decision making process. J Cancer Educ. 2014;29(1):44-49.

12. Hussain SK, Altieri A, Sundquist J, Hemminki K. Influence of education level on breast cancer risk and survival in Sweden between 1990 and 2004. Int J Cancer. 2008;122(1):165-169.

13. Hajian-Tilaki K, Kaveh-Ahangar T, Hajian-Tilaki E. Is educational level associated with breast cancer risk in Iranian women?. Breast Cancer. 2012;19(1):64-70.

14. Lestari AAW, Prabawa IPY, Wiranata S, Supadmanaba IGP. High eosinophils lymphocyte ratio (ELR) related with subtype of breast cancer in Sanglah General Hospital, Bali. Annals of Oncology. 2018;29(Suppl 9):ix11-ix12

15. Wiranata S, Adiputra PAT, Lestari AAW, Prabawa IPY, Supadmanaba IGP. Platelet Lymphocyte Ratio (PLR) Related with Clinicopathological Characteristics of Balinese Women Breast Cancer Patient. Annals of Oncology. 2019;30(Suppl 6):vi144

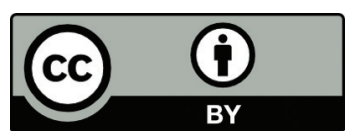

This work is licensed under a Creative Commons Attribution 